\title{
PERAN PEMBELAJARAN SENI TARI DALAM PENGEMBANGAN KEMAMPUAN MOTORIK SISWA KELAS V SDN KOSAMBI I KABUPATEN TANGERANG
}

\author{
${ }^{1}$ Hanif Rismillatus Syaidah, ${ }^{2}$ Eka Yulyawan Kurniawan \\ Universitas Muhammadiyah Tangerang, Jl.Perintis Kemerdekaan 1 No.33 Cikokol Tangerang \\ e-mail : hanifrismilla@gmail.com, Ekayeka88@gmail.com
}

\begin{abstract}
Abstrak
Pembelajaran seni tari perlu diajarkan pada tingkat sekolah dasar karena mempunyai manfaat untuk pertumbuhan dan perkembangan siswa, salah satunya berperan untuk mengasah kemampuan motorik. Penelitian ini bertujuan untuk (1) mengetahui peran pembelajaran seni tari dalam pengembangan kemampuan motorik siswa kelas V; (2) mengetahui kemampuan motorik siswa kelas V. Penelitian ini menggunakan metode kualitatif. Subjek penelitian adalah guru seni tari dan siswa kelas V. Data primer diperoleh dari hasil wawancara dengan guru seni tari dan siswa kelas VA. Data sekunder diperoleh dari arsip resmi SD Negeri Kosambi 1 Kabupaten Tangerang. Metode pengumpulan data yang digunakan adalah observasi, wawancara, dokumentasi, proses kemampuan motorik siswa (tes perfomance), dan angket. Hasil analisis menunjukkan bahwa kemampuan motorik siswa dapat dikembangkan dengan menari. Setiap tahap dalam pembelajaran seni tari memberikan andil yang berbeda- beda dalam perkembangan motorik.
\end{abstract}

Kata Kunci : Kemampuan Motorik, Pembelajaran Seni Tari, Peran Seni Tari

\begin{abstract}
Learning dance needs to be taught at the elementary school level because it has the growth and development of students, one of them has role to hone motor skills. This study aims to (1) determine the role of dance learners in developing motor skills of fifth grade students; (2) determine the motor skills of class V students. This study use a qualitative method. Subjects were dance teachers and grade V students. Secondary data were obtained from official archives of Kosambi 1 Primary School, Tangerang Regency. The data collection methods used were observation, interviewers, documentation, the process of students motor skills (perfomance tests), and questionnaire. The results of the analysis showed that students motor skills could be developed by dancing. Each stage in learning dance gave a different contribution to motor development.
\end{abstract}

Keyword: Motor Skills, Learning Dance, The Role Of Dance 


\section{PENDAHULUAN}

Pendidikan seni budaya merupakan salah satu perwujudan agar dapat mengembangkan potensi yang ada dalam diri siswa. Pendidikan seni melibatkan semua bentuk kegiatan berupa aktivitas fisik dan cita rasa keindahan yang tertuang dalam kegiatan berekspresi, bereksplorasi, berapresiasi melalui gerak, rupa dan bunyi. Secara tidak langsung, menari memberikan pembelajaran kepada siswa untuk berkreasi dan beraktivitas.

Menurut Pengeran Suryadiningrat (2017) tari adalah gerak dari seluruh anggota tubuh manusia yang disusun selaras dengan irama musik serta mempunyai maksud tertentu (Mulyani, h.37). Jadi, gerak-gerik dalam tari harus diungkapkan secara ritmis, sehingga memunculkan karakteristik tertentu sesuai dengan kualitas ritme yang dimunculkan.

Mendidik melalui seni tidak mudah, pengajar atau pendidik harus mempunyai bekal keilmuan yang mempuni, apalagi kesenian daerah yang memiliki kearifan lokal, karena selain memberikan ilmu pengetahuan kepada siswa, pengajar juga ikut serta dalam mewariskan nilai-nilai budaya Indonesia. Dengan kegiatan menari banyak manfaat yang bisa ditemukan, seperti melatih bakat, keberanian, minat, percaya diri, kerjasama, dan motorik. Kemampuan motorik adalah kemampuan yang diperoleh dari keterampilan penampilan dan gerak umum yang akan mencerminkan kemampuan gerak seseorang dalam mempelajari suatu gerakan secara kualitas dan kuantitas yang baik.

Kemampuan motorik siswa dapat dibedakan menjadi dua yaitu aktivitas motorik kasar dan aktivitas mototrik halus (Rohendi \& Seba, 2017). Aktivitas motorik kasar berkalitan dengan keterampilan gerak. Misalnya, berlari, menendang dan lain sebagainya. Berbeda dengan aktivitas motorik halus yang berkaitan dengan keterampilan fisik. Misalnya bermain puzzle, memasukkan benda ke dalam lubang sesuai dengan bentuknya dan lain sebagainya.

Pembelajaran merupakan proses komunikasi antara guru dengan siswa. Nur Latifah dan Fitrian (2018) menjelaskan, pembelajaran adalah suatu konsep dari dua dimensi kegiatan (belajar dan mengajar) yang harus direncanakan dan diaktualisasikan, serta diarahkan pada pencapaian tujuan atau penguasaan sejumlah kompetensi dan indikatornya sebagai gambaran hasil belajar (h.17).

Menurut Suyono dan Hariyanto (2014) tujuan pembelajaran yang ideal adalah agar daftar murid mampu mewujudkan perilaku belajar yang efektif, diantaranya seperti yang seperti yang dinyatakan oleh Ian James Mitchell dalam disertasinya yang diujikan di Monash Unversity, Melbourne berjudul Teaching for Quality Learning (tidak dipublikasikan, 1993), 
diantaranya sebagai berikut : 1) Perhatian siswa yang katif dan terfoks kepada pembelajaran; 2) Siswa mampu menjelaskan hasil belajarnya; 3) Siswa difasilitasi untuk berani menyatakan kepada guru apa-apa yang belum dipahami; 4) Siswa berani menyatakan ketidaksetujuan, dan lain sebagainya (h.209).

Tari merupakan salah satu unsur kebudayaan dalam kehidupan masyarakat. Seni tari termasuk dalam salah satu cabang seni yang menggunakan tubuh sebagai media ungkap. Menurut Susan, tari adalah gerak-gerak yang dibentuk secara ekspretif yang diciptakan manusia untuk dapat dinikmati (Astuti, 2016, h.6). Rusliana berpendapat, nilai-nilai keindahan tari terletak pada empat hal yaitu wiraga. wirasa, wirama, dan harmoni (Mulyani, 2017, h.37).

Unsur-unsur dasar tari menurut Mulyani (2017) yaitu tenaga, ruang, dan waktu (h.39). Tari memberikan penghayatan rasa, empati, simpati, dan kepuasan tersendiri terutama bagi pendukungnya. Menurut Mulyani (2016) tari dalam artian yang sederhana adalah gerak yang indah dan lahir dari tubuh yang bergerak dan berirama (h.49). Gerakan tubuh dapat dinikmati sebagai bagaian dari komunikasi bahasa tubuh. Mendidik melalui seni tidak mudah, karena selain memberikan ilmu pengetahuan kepada siswa, pengajar juga ikut serta dalam mewariskan nilai-nilai budaya Indonesia.

Kemampuan motorik dapat digambarkan sebagai kemampuan seseorang dalam melakukan aktivitas. Rohendi \& Seba (2017) berpendapat, motorik adalah semua gerakan tubuh, meliputi gerak internal yang tidak teramati (motor) yaitu penangkapan stimulus oleh indera-penyampaian stimulus oleh susunan saraf sensorik ke otak (memori)-pemrosesan dan pembuatan keputusan oleh otak- penyampaian keputusan oleh susunan saraf motorik ke otot, dan gerak eksternal yang teramati (movement) (h.20). Menurut Rohendi \& Seba (2017) motorik adalah proses laten, yang berawal dari penangkapan rangsang (auditif, visual, taktil, dan kinestetik) oleh alat-alat indera, pemrosesan rangsang-rangsang tersebut dan pembuatan keputusan oleh otak dan pelaksanaan gerak aktual yang teramati (h.30).

Decaprio berpendapat (2013) saat seorang siswa melakukan pembelajaran motorik di sekolah, perubahan nyata yang terjadi ialah meningkatnya mutu keterampilan motorik. Ini dapat diukur dengan beberapa cara. Salah satunya adalah dengan melihat keberhasilan sorang siswa dalam melakukan gerakan yang semuka belum dikuasainya (h. 17).

Perkembangan keterampilan motorik sebenarnya tidak berpengaruh terhadap kecerdasan intelektual. Artinya, seorang siswa yang memiliki otak cerdas bisa saja tidak mempunyai kemampuan motorik yang mumpuni. Sebaliknya, seorang siswa yang memiliki 
otak biasa-biasa saja justru mempunyai keterampilan motorik yang luar biasa, bahkan melebihi seorang siswa yang cerdas (h.19-20).

Decaprio menjelaskan, pembelajaran motorik di sekolah tidak dapat terlepas dari unsur-unsur pokok yang meliputi kekuatan, kecepatan, power, ketahanan, kelincahan, keseimbangan, fleksibilitas, dan koordinasi (h.42).

\section{METODE PENELITIAN}

Penelitian ini dilaksanakan di SD Negeri Kosambi 1 Kabupaten Tangerang. Metode yang digunakan merupakan deskriptif kualitatif yang bertujuan untuk mendeskripsikan peran pembelajaran seni tari dalam pengembangan kemampuan motorik siswa. Menurut Sugiyono (2009) penelitian kualitatif harus bersifat "pespektif emic" artinya memperoleh data bukan "sebagaimana seharusnya", bukan berdasarkan apa yang dipikirkan oleh peneliti, tetapi berdasarkan sebagaimana adanya yang terjadi di lapangan, yang dialami, dirasakan, dan dipikirkan oleh partisipan / sumber data (h.387-388). Sukmadinata (2017) berpendapat, penelitian deskriptif adalah suatu bentuk penelitian yang paling dasar. Ditunjukkan untuk mendeskripsikan atau menggambarkan fenomena-fenomena yang ada, baik fenomena yang bersifat alamiah ataupun rekayasa manusia (h.72). Objek penelitian ini adalah siswa kelas V. Teknik pengumpulan data menggunakan teknik triangulasi yaitu observasi, wawancara, dokumentasi, tes perfomance, dan angket.

\section{TEMUAN DAN PEMBAHASAN}

Hasil penelitian ini diperoleh dari hasil wawancara mengenai peran pembelajaran seni tari dalam pengembangan kemampuan motorik siswa dan kemampuan motorik siswa kelas VA SD Negeri Kosambi 1 Kabupaten Tangerang. Data sekunder adalah data pendukung dari arsip dan dokumen resmi sekolah serta dokumen yang relevan dengan peran pembelajaran seni tari dalam pengembangan kemampuan motorik siswa.

Berikut rata-rata kemampuan siswa memperagakan keindahan gerak tari sesuai dengan nilai keindahan menggunakan rubrik hasil penelitian yang didapat melalui tes perfomance pembelajaran seni tari dapat dilihat sebagai berikut : 


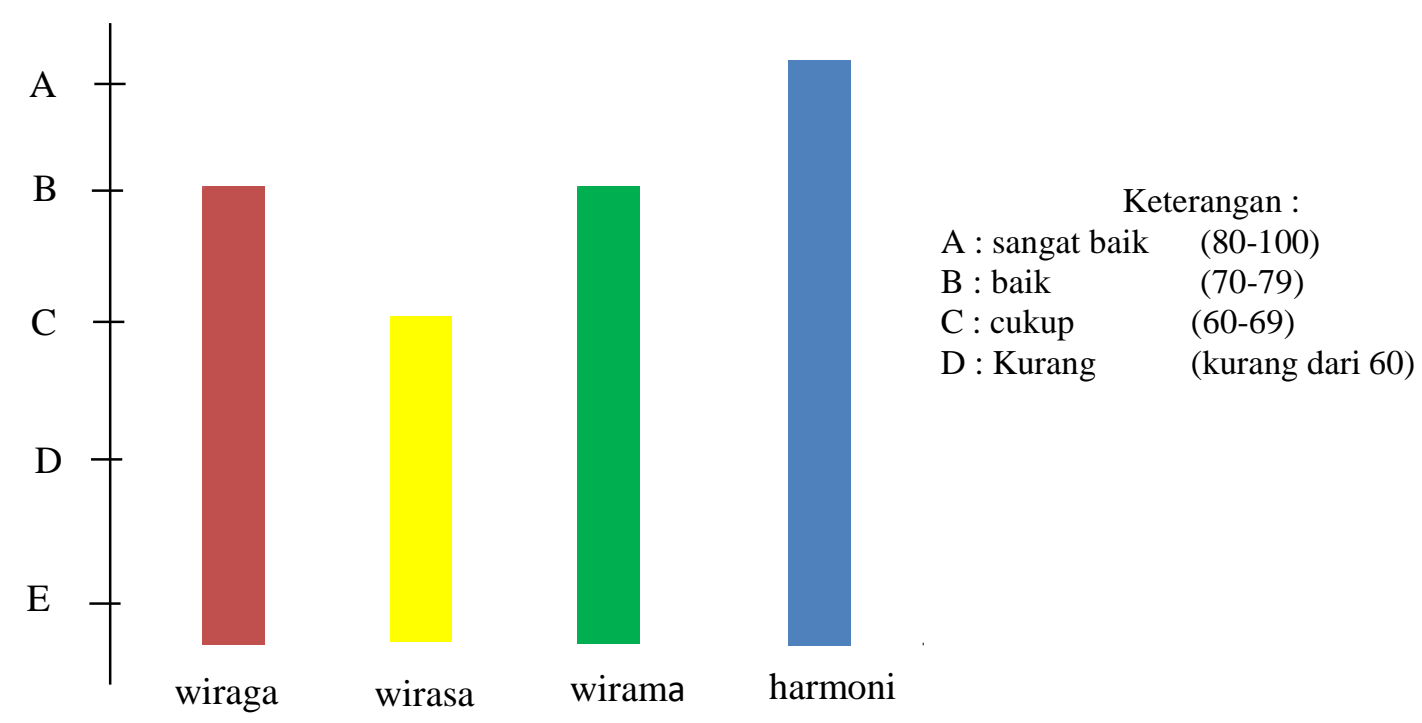

Berdasarkan rubrik hasil penelitian yang didapat melalui tes perfomance pembelajaran seni tari menunjukkan kemampuan siswa dalam memunculkan nilai-nilai keindahan tari sebanyak 9 siswa dengan kategori sangat baik, 18 siswa dengan kategori baik, dan 7 siswa dengan kategori cukup. Observasi kemampuan motorik kasar cenderung dimiliki oleh siswa laki-laki. Sedangkan siswa perempuan cenderung lebih dominan kemampuan motorik kasarnya.

Kemampuan motorik siswa dapat dikembangkan dengan menari, baik itu kemampuan motorik kasar maupun kemampuan motorik halus. Kemampuan motorik kasar setelah siswa melaksanakan pembelajaran seni tari dapat dilihat dari kemampuan siswa melakukan gerakan meloncat, berjalan, memanjat, berlari, menangkap bola maupun menendang bola (Decaprio, 2013, h.42). Siswa akan lebih leluasa melakukan mobilitas dalam melaksanakan aktivitas sehari-hari. Kemampuan motorik halus setelah melaksanakan pembelajaran seni tari dapat dilihat dari kemampuan siswa menyelesaikan tugas yang melibatkan jari-jari tangan. Siswa mampu bermain musik dengan harmonis, melukis dan menggambar tanpa mengalami kesulitan berarti, serta dapat menulis dengan rapi. 
Tabel 1.1 Data Hasil Kuesioner dengan Guru Tari dan Sembilan Murid / Orang Tua Siswa

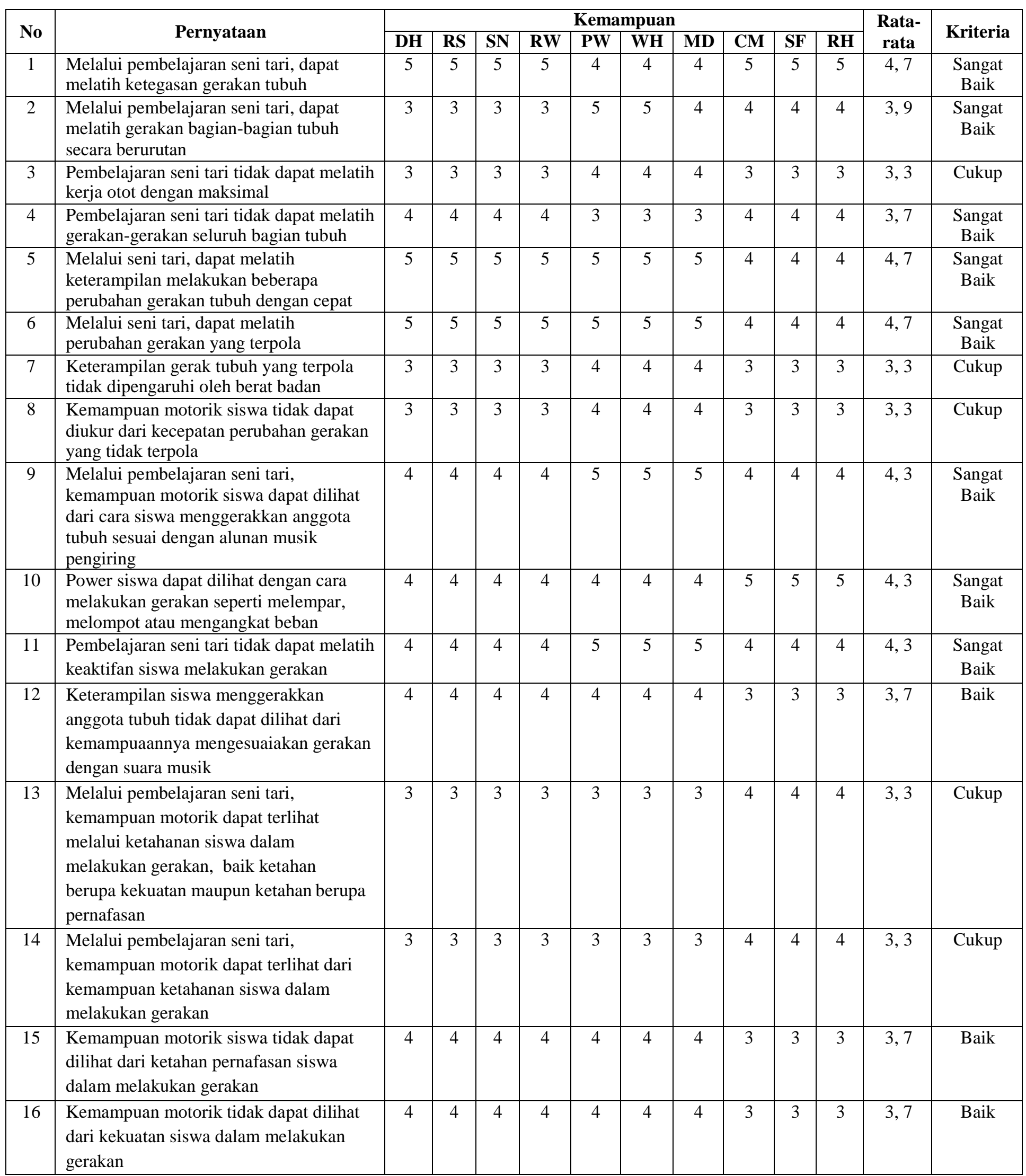




\begin{tabular}{|c|c|c|c|c|c|c|c|c|c|c|c|c|c|}
\hline \multirow{2}{*}{ No } & \multirow{2}{*}{ Pernyataan } & \multicolumn{10}{|c|}{ Kemampuan } & \multirow{2}{*}{$\begin{array}{c}\text { Rata- } \\
\text { rata }\end{array}$} & \multirow{2}{*}{ Kriteria } \\
\hline & & DH & $\mathbf{R S}$ & $\mathbf{S N}$ & $\mathbf{R W}$ & PW & WH & MD & $\mathbf{C M}$ & SF & RH & & \\
\hline 17 & $\begin{array}{l}\text { Melalui pembelajaran seni tari, } \\
\text { kemampan motorik siswa dapat dilihat } \\
\text { dari pergerakan cepat dari posisi satu } \\
\text { ke posisi lainnya }\end{array}$ & 4 & 4 & 4 & 4 & 4 & 4 & 4 & 5 & 5 & 5 & 4,3 & $\begin{array}{c}\text { Sangat } \\
\text { Baik }\end{array}$ \\
\hline 19 & $\begin{array}{l}\text { Kemampuan motorik tidak dapat } \\
\text { diukur dari kecepatan siswa } \\
\text { melakukan pola lantai }\end{array}$ & 3 & 3 & 3 & 3 & 4 & 4 & 4 & 4 & 4 & 4 & 3,6 & Baik \\
\hline 21 & $\begin{array}{l}\text { Kemampuan motorik siswa dapat } \\
\text { terlihat dari cara siswa mengendalikan } \\
\text { gerakan-gerakan tari yang } \\
\text { dilakukannya }\end{array}$ & 5 & 5 & 5 & 5 & 4 & 4 & 4 & 4 & 4 & 4 & 4,4 & $\begin{array}{l}\text { Sangat } \\
\text { Baik }\end{array}$ \\
\hline 22 & $\begin{array}{l}\text { Kemampuan motorik siswa dapat } \\
\text { terlihat dari cara mereka merespon } \\
\text { gerak efisien dan gerak dasar sebuah } \\
\text { tari }\end{array}$ & 4 & 4 & 4 & 4 & 3 & 3 & 3 & 4 & 4 & 4 & 3,7 & Baik \\
\hline 23 & $\begin{array}{l}\text { Kemampuan motorik siswa tidak dapat } \\
\text { dilihat dari cara mengendalikan } \\
\text { gerakan tari yang dilakukaknnya }\end{array}$ & 3 & 3 & 3 & 3 & 4 & 4 & 4 & 3 & 3 & 3 & 3,3 & Cukup \\
\hline 26 & $\begin{array}{l}\text { Melalui pembelajaran seni tari, } \\
\text { kemampuan gerakan yang fleksibel } \\
\text { dapat dilatih secara bertahap }\end{array}$ & 4 & 4 & 4 & 4 & 5 & 5 & 5 & 4 & 4 & 4 & 4,3 & $\begin{array}{c}\text { Sangat } \\
\text { Baik }\end{array}$ \\
\hline 27 & $\begin{array}{l}\text { Gerakan tubuh yang fleksibel tidak } \\
\text { dapat dilatih melalui pembelajaran } \\
\text { seni tari }\end{array}$ & 4 & 4 & 4 & 4 & 3 & 3 & 3 & 5 & 5 & 5 & 4,0 & Baik \\
\hline 28 & $\begin{array}{l}\text { Kemampuan motorik hanya dapat } \\
\text { diukur dengan melihat fleksibilitas } \\
\text { tubuh siswa dalam melakukan } \\
\text { beberapa gerakan tari }\end{array}$ & 3 & 3 & 3 & 3 & 3 & 3 & 3 & 4 & 4 & 4 & 3,3 & Cukup \\
\hline 29 & $\begin{array}{l}\text { Kemampuan motorik siswa dapat } \\
\text { dilihat dari kemampuannya } \\
\text { melakukakan jenis gerakan secara } \\
\text { tangkas, seimbang dan cepat }\end{array}$ & 4 & 4 & 4 & 4 & 5 & 5 & 5 & 4 & 4 & 4 & 4,3 & $\begin{array}{c}\text { Sangat } \\
\text { Baik }\end{array}$ \\
\hline 30 & $\begin{array}{l}\text { Kemampuan motorik siswa dapat } \\
\text { dilihat dari kemampuannya melakukan } \\
\text { gerakan yang sederhana ke dalam } \\
\text { bentuk gerakan yang lebih bervariasi }\end{array}$ & 5 & 5 & 5 & 5 & 4 & 4 & 4 & 4 & 4 & 4 & 4,4 & $\begin{array}{c}\text { Sangat } \\
\text { Baik }\end{array}$ \\
\hline
\end{tabular}




\begin{tabular}{|c|c|c|c|c|c|c|c|c|c|c|c|c|c|}
\hline No & Pernyataan & \multicolumn{10}{|c|}{ Kemampuan } & $\begin{array}{c}\text { Rata- } \\
\text { rata }\end{array}$ & Kriteria \\
\hline 32 & $\begin{array}{l}\text { Melalui pembelajaran seni tari, } \\
\text { kemampuan motorik tidak dapat } \\
\text { diukur melalui gerakan tangkas, } \\
\text { seimbang dan cepat }\end{array}$ & 4 & 4 & 4 & 4 & 3 & 3 & 3 & 3 & 3 & 3 & 3,4 & Baik \\
\hline \multicolumn{2}{|c|}{ Jumlah Skor } & 122 & 122 & 122 & 122 & 126 & 126 & 124 & 124 & 124 & 124 & \multicolumn{2}{|l|}{123,8} \\
\hline \multicolumn{12}{|c|}{ Rata-rata skor akhir } & 3,86 & Baik \\
\hline
\end{tabular}

Pada tabel di atas diketahui jumlah skor 123,8 dan rata-rata akhir skor adalah 3,86 dari hasil evaluasi guru seni tari dan sembilan wali murid / orangtua siswa. Maka apabila dikonversikan ke dalam data kualitatif termasuk ke dalam kategori "Baik". Dengan demikian, proses pembelajaran seni tari berpengaruh baik terhadap pengembangan kemampuan motorik siswa kelas VA.

Pelaksanaan pembelajaran seni tari di SD Negeri Kosambi 1 Kabupaten Tangerang sudah dilaksanakan rutin setiap hari Sabtu. Mulyani (2016) berpendapat tari dalam artian yang sederhana adalah gerak yang indah dan lahir dari tubuh yang bergerak dan berirama (h.49). Penulis berpendapat bahwa seni tari merupakan ungkapan perasaan manusia yang dinyatakan dengan gerakan-gerakan tubuh manusia yang disesuaikan dengan ritme dan mempunyai maksud tertentu.Bentuk gerak yang terdapat di dalam pembelajaran tari, disesuaikan dengan karakteristik tari anak sekolah dasar agar sesuai dengan tingkat perkembangan siswa. Penyesuaian gerak tari bertujuan agar siswa dapat mengemabngakan bakat dan hobi dibidang tari dengan baik. Seni tari memiliki peran yang besar untuk siswa, yaitu mengembangkan segenap talenta dan bakat yang dimiliki oleh siswa.

Pembelajaran seni tari yang dilaksankan secara rutin, akan mengasah kemampuan motorik siswa, karena siswa dituntut untuk selalu bergerak sesuai dengan iringan musik. Proses pembelajaran seni tari di SD Negeri Kosambi 1 Kabupaten Tangerang, dimulai dengan berbaris dengan rapi, berdoa dan melakukan pemanasan. Pemanasan dimaksudkan agar nantinya siswa dapat melakukan gerakan tari dengan lentur. Kelenturan gerakan akan memungkinkan siswa mempraktikan gerakan dengan luwes. Siswa yang melakukan gerakan luwes, berarti siswa dapat memaksimalkan koodinasi gerak antara bagian tubuh yang satu dengan yang lain. Karakteristik anak sekolah dasar menurut Sumantri (2015) terdiri dari anak 
suka bermain, anak senang bermain, anak senang bergerak, anak senang bekerja dalam kelompok, dan anak senang merasakan atau melakukan serta memperagakan sesuatu secara langsung (h. 154-155).

Penilaian seni tari memperhatikan unsur wiraga, wirasa, wirama dan harmoni. Keempat unsur tersebut kemudian dipakai sebagai suatu cara untuk mengevaluasi kualitas penari dan menjadi sistem pengkategorian yang lazim digunakan sebagai tolak ukur dalam tari. Menurut Rusliana nilai-nilai keindahan tari terletak pada empat hal yaitu wiraga, wirasa, wirama, dan harmoni. Wiraga adalah ungkapan secara fisik dari awal sampai akhir menari. Wirasa merupakan penjiwaan atau kemampuan penari dalam mengungkapkan rasa emosi yang sesuai dengan isi atau tema dari tarian tersebut. Wirama merupakan ketajaman rasa atau kepekaan penari pada irama yang luluh menyatu dengan setiap ungkapan geraknya. Harmoni adalah penekanan pada interelasi yang menyeluruh dari tarian yang dibawakan oleh penari. Dengan kata lain, keselarasan antara kemampuan wiraga, wirama, dan wirasa (Mulyani, 2017, h.37).

Penilaian secara wiraga, siswa dituntut untuk melakukan gerakan tarian dengan benar sesuai dengan gerakan yang dicontohkan oleh guru tari dan kompak. Penilaian wiraga dalam penilaian kemampuan motorik dapat dilihat dari bentuk gerak yang dipraktikan siswa ketika menari. Penilaian wirasa dalam penilaian kemampuan motorik dapat diulihat dari penghayatan, penjiwaan, dan pengungkapan rasa emosi yang sesuai dengan isi tarian. Penilaian wirama dalam penilaian kemampuan motorik dapat dilihat dengan memperhatikan setiap gerakan yang dilakukan apakah seirama dengan iringan musik dan kapan suatu geralan jatuh pada iringannya. Hasil observasi di lapangan menunjukkan bahwa siswa dapat dilatih mengembangkan kemampuan motoriknya dengan menari. Kemampuan motorik siswa dapat ditunjukkan dengan kecepataan, kekuatan, ketahanan dan kelincahan ketika bergerak. kekuatan, kecepataan, power, ketahanan, kelincahan, keseimbangan, fleksibiliti, dan koordinasi ketika bergerak adalah unsur-unsur pokok dalam pembelajaran motorik.

\section{KESIMPULAN}

Peran pembelajaran seni tari di sekolah memiliki fungsi untuk membantu pertumbuhan dan perkembangan siswa, baik secara fisik, mental maupun estetik. Pembelajaran seni tari mampu mengembangkan kemampuan motorik siswa karena pembelajaran seni tari menuntut siswa untuk bergerak dan pastinya bagus untuk tumbuh kembang serya perkembangan motoriknya. Pembelajaran seni tari yang dilaksanakan secara rutin akan mengasah kemampuan motorik siswa. 


\section{DAFTAR PUSTAKA}

Abdurrahman, M (2012). Anak Berkesulitan Belajar. Jakarta: Rineka Cipta.

Arifin, Z (2016). Evaluasi Pembelajaran. Bandung: PT Remaja Rosdakarya.

Astuti, F (2016). Pengetahuan \& Teknik Menata Tari Untuk Anak Usia Dini. Jakarta: Kencana.

Decaprio, $\mathrm{R}$ (2013). Aplikasi Pembelajaran Motorik Di Sekolah. Jogjakarta: DIVA Press.

Dimyati \& Mudjiono (2015). Belajar \& Pembelajaran. Jakarta: Rineka Cipta.

Djamarah, S. B. (2011). Psikologi Belajar. Jakarta: PT Asdi Mahasatya.

Emzir (2014). Metodologi Penelitian Kualitatif Analisis Data. Jakarta : Rajawali Pers.

Imani, F., Masganti, S., \& Suryani, I (2017). Upaya meningkatkan Kamampuan Motorik Kasar Anak Usia 5-6 Tahun melalui Kegiatan Menari Animal Chiken Dance. Raudhah Program Studi Pendidikan Guru Raudhatul Athfal (PGRA), 05 (02),

Kurniawan, E. Y. (2017). Pendidikan Berbasis Kearifan Lokal dalam Ektrakurikuler Degung di SDN Mekarsari II Kabupaten Tangerang. Jurnal Basic PSGD Universitas Muhammadiyah Tangerang

Kusumastuti, E (2014). Penerapan Model Pembelajaran Seni Tari Terpadu Pada Siswa Sekolah Dasar. Mimbar Sekolah Dasar, 1 (1), 7-16

Mahmud (2017).Psikologi Pendidikan. Bandung: CV Pustaka Setia

Sugiyono (2008). Metode Penelitian Pendidikan. Bandung: Alfabeta.

Suyono \& Hariyanto (2014). Belajar dan Pembelajaran. Bandung: PT Remaja Rosdakary 